\title{
Applying a reflexive framework to evaluate a communication skills curriculum
}

\author{
Lawrence Cheung \\ Department of Medicine, University \\ of Alberta, Edmonton, AB, Canada
}

This article was published in the following Dove Press journal:

Advances in Medical Education and Practice

14 October 2016

Number of times this article has been viewed

\begin{abstract}
After creating and delivering an educational curriculum, medical educators must ultimately evaluate the effectiveness of the implemented curriculum. Seasoned educators can benefit from using an established framework to help them structure a thorough, complete curricular evaluation; however, novice educators may have difficulty in transforming the concept of evaluation into a concrete process. The RUFDATA (Reasons and purpose, Uses, Focus, Data and evidence, Audience, Timing, and Agency) framework is one such paradigm. It is a well-recognized tool consisting of a reflexive framework that can guide medical educators to evaluate their own medical education curriculum. Just as important, it enables medical educators to reflect on the reasons behind the evaluation. This insight, in turn, can foster a spirit of evaluation, thus helping to ingrain it into the local educational culture. By using the evaluation of our communication skills curriculum as an example, this article describes how educators can apply the RUFDATA framework to evaluate their own curriculum.
\end{abstract}

Keywords: curriculum evaluation, RUFDATA, communication skills, course evaluation, reflexive evaluation

\section{Introduction}

Once medical educators have developed and implemented a curriculum for their learners, they must evaluate the effectiveness of that curriculum to ensure if it is fulfilling its intended purpose. ${ }^{1,2}$ Here, we define curriculum evaluation as gathering information or data about an educational program to judge its merit. ${ }^{3}$

However, a proper curricular evaluation can be difficult to conduct for faculty who lack experience or tools to methodically plan the evaluation. ${ }^{46}$ A reflexive framework known as RUFDATA (Reasons and purpose, Uses, Focus, Data and evidence, Audience, Timing, and Agency) is a tool that can transform the concept of evaluation into a concrete process. ${ }^{7}$

This article shows how medical educators can use the RUFDATA framework to plan and conduct an evaluation of their own curriculum. After providing a brief account of our communication skills curriculum, this article gives an overview of the RUFDATA framework and describes how to employ each component of the framework to conduct curricular evaluation, using the evaluation of our communication skills curriculum as an example.

\section{Background}

Teaching communication skills is an essential component of the curriculum in residency education. ${ }^{8,9}$ For our 2-year subspecialty residency program in respirology, we first 
performed an analysis with past cohorts of residents about their needs. Then, we developed and implemented a communication skills curriculum after reviewing the methods to teach communication skills in the literature. Our curriculum thus included several small group seminars that incorporated active learning, ${ }^{10-13}$ reflective essay assignments, ${ }^{14}$ and simulation exercises ${ }^{15-17}$ and covered topics such as writing proper consultation letters, communicating with patients and their families, collaborating with allied health professionals, and giving effective presentations.

\section{RUFDATA framework}

The RUFDATA framework by Saunders ${ }^{7}$ asks 7 questions that educators should ponder when planning their curricular evaluation. Reflexive questioning ${ }^{18}$ (ie, by asking open-ended questions to help the educator reflect on many possible options) helps start the evaluation process by addressing key aspects of the evaluation's design. In other words, it helps educators decide what they want to get out of the evaluation and thus to plan and execute it accordingly.

\section{Reasons}

First, educators should ask themselves the reasons for evaluating the curriculum as the answer(s) to this question will be the answers to the rest of the questions in the RUFDATA framework. Broadly speaking, a curriculum is evaluated to demonstrate accountability to various stakeholders, to develop further knowledge about the curricular topic, and to improve the curriculum itself. ${ }^{19}$

We specifically wanted to evaluate our communication skills curriculum to ensure that our residency program was meeting accreditation standards in this specific area, the first small step in evaluating all aspects of our residency curriculum. We also wanted to ensure that our residents were learning the requisite skills to work with allied health professionals and were communicating effectively with patients and their families. In addition, we sought to determine whether there was any effect on the residents' communication skills during their teaching presentations and whether there were any unplanned learning experiences occurring, such as "curriculum drift" 20 and a "hidden curriculum", ${ }^{21-25}$ which failed to match the expectations of our planned curriculum.

\section{Uses}

After reflecting on the reasons behind the evaluation, educators should ask how the information gathered will be used. In other words, what action can and/or will be taken once the data are collected and the results of the evaluation are known? How the information will be used, in turn, informs the focus of the evaluation and the data one collects.

We planned to use the information for ongoing quality improvement of our program ie, to conduct formative evaluation. ${ }^{26}$ The information gained from our evaluation would enable us to efficiently target areas for improvement in our teaching and assessment of communication skills for the residents. We also wanted to incorporate the evaluation results into our organizational database ${ }^{27}$ to allow future residency program directors to see what worked (and did not work) for us. If insufficient resources such as money, time, and personnel were found to be the cause of any deficiencies in our curriculum, we planned to use our evidence to lobby for investment in these resources. Finally, we sought to demonstrate our compliance in this domain for accreditation.

\section{Focus}

As it is difficult to thoroughly evaluate an entire teaching curriculum at once, educators should focus their evaluation on key aspects of the curriculum. The focus, in turn, influences the data that will be collected.

We selected to focus on the adequacy of the residents' consultation letters, their written and verbal communication with allied health professionals, their verbal communication with patients and families, and their presentation skills during visits.

There are many other areas where a communication skills curriculum can be important, such as teaching proper patient care handover, ${ }^{28-30}$ discharge summary dictation, ${ }^{31-33}$ and crisis resource management. ${ }^{34-36}$ However, we chose to evaluate these other aspects of our curriculum in the future as we did not yet have the tools to assess the residents' performance in these areas.

\section{Data and evidence}

After reflecting on the reasons, uses, and focus of the evaluation, educators must select the tools that they will use to collect the data and evidence necessary for the evaluation. This usually involves measuring how well the learners have achieved the learning objectives ${ }^{37}$ or measuring both the unintended and intended accomplishments of the learners. ${ }^{38}$ Some even focus on the learners' pursuit of accomplishment, rather than the actual accomplishment itself. ${ }^{39}$ Typically, the data collection tools assess the achievements of the learners. ${ }^{40}$ These assessments include observation of behavior in the clinical workplace, ${ }^{41-44}$ observation of behavior during an objective structured clinical examination (OSCE) or simulation exercise, ${ }^{45-51}$ and chart review or audit. ${ }^{52-57}$ In 
addition, feedback can also be gathered from the learners and/or new graduates, through interviews or questionnaires, to determine if the teaching program has met their perceived needs. ${ }^{58-60}$

Our data consisted of random audits of the residents' consultation letters, multisource assessment of the residents' communication skills by allied health professionals (specifically, the nurses and ward unit clerk), and faculty's assessment of the residents' communication skills during presentations. We chose these tools because we were already using them before implementing our new curriculum and had baseline results with which we could compare. We considered using feedback from patients and their families but had not yet implemented this form of assessment during our evaluation. Instead, we used the faculty's direct observations of the residents' communication with patients and families, realizing the potential limitations of this approach. ${ }^{61}$ Additionally, we conducted exit interviews with the residents to look for any hidden curriculum or unintended consequences from our formal curriculum.

\section{Audience}

Educators should decide who the audience of the evaluation will be. In other words, who will see the results of the evaluation? The answer, in turn, depends on the level of decisionmaking informed by the evaluation. ${ }^{62}$ Medical educators overseeing the teaching program can use the evaluation to determine the need for improvement. They may wish to share this information with their peers who can then enhance their own teaching programs. Accreditation organizations may use the information as proof of compliance for this facet of the whole academic program. And the evaluation results, if positive, can bolster the teaching faculty's morale and validate their teaching efforts.

We chose to share our evaluation results with our residency program committee tasked with implementing and revising the curriculum. In addition, we decided to keep the results as part of our records for accreditation and also share them with our teaching faculty.

\section{Timing}

The timing of the evaluation is another decision that educators must contemplate. For example, we conducted our evaluation 6 months before the start of the upcoming academic year. This enabled us to ensure that we had collected and analyzed all the data and that we would have sufficient time to contemplate and implement the necessary changes at the beginning of the academic year involving the next cohort of learners.

\section{Agency}

Here, educators must consider who will conduct the evaluation. Both internal evaluators (ie, people already familiar with the program or who may have helped develop it) and external evaluators have their own advantages and disadvantages. For example, an internal evaluator acquainted with the intricacies of the program and local quirks of the educational environment may probe deeper to look for weaknesses or may be more available to conduct the evaluation. On the other hand, an external evaluator might possess greater objectivity or garner more legitimacy. ${ }^{63}$ Potential disadvantages of an external evaluator include a greater cost (eg, for transportation and lodging) and difficulty in coordinating the schedule for evaluation.

After careful consideration, the program director of our residency training program, one of the developers of the curriculum, conducted the evaluation.

\section{Evaluation results}

We analyzed the data during the 12 months before and after the implementation of our communication skills curriculum.

For the evaluation of the residents' consultation letters, we used a 9-item, 5-point scoring scale (for a maximum score of 45) developed by Keely et al ${ }^{54}$ to analyze features such as content, style, organization, and educational value. We randomly selected 3 consultation letters written by each resident. Prior to implementation of our curriculum, the mean score was 32.8 with a SD of 4.4 , whereas after implementation, the mean score improved to 40 with a SD of 2.9.

For the multisource assessment of the residents' communication skills by allied health care professionals, we asked the nurses and pulmonary ward unit clerk to rate 4 aspects of the residents' verbal and written communication as either unsatisfactory or satisfactory. Virtually, all residents achieved a satisfactory rating before and after implementation of our curriculum. On reflection, our rating scale had only 2 options - that is, satisfactory and unsatisfactory. Thus, we were likely unable to detect nuanced differences in performance. There did not appear to be any significant, unintended deterioration in the residents' behavior with the new curriculum (within the limits of our evaluation).

Using direct observation, faculty rated the residents' communication with patients and their families using a 5 -point scale from 1 (poor) to 5 (excellent). Among 24 encounters observed before implementing our curriculum, 6 encounters received a score of 3 (adequate), 13 received a score of 4 (good), and 5 received a score of 5, with no encounters receiving a score of 1 or 2 (borderline). Among 
20 encounters observed after implementing our curriculum, there seemed to be overall improvement with 2 encounters receiving a score of 3,8 receiving a score of 4 , and 10 receiving a score of 5 .

Faculty also rated the residents' communication skills during presentations using a 3-point scale (1, poor; 2, adequate; and 3 , excellent). Out of 12 presentations given before implementing our curriculum, 1 received a score of poor, 7 received a score of adequate, and 4 received a score of excellent. Overall, scores improved after implementation where, among 10 presentations, 4 received a score of adequate and 6 received a score of excellent, with none receiving a score of poor.

During individual exit interviews, residents uniformly felt that the curriculum improved their written and verbal communication skills and felt that the faculty modeled the curriculum. We could find no instances where the formal curriculum conflicted with the learning environment.

Overall, we felt that we were meeting the accreditation standards, our residents were acquiring the communication skills that were the focus of our evaluation, and that there were no unintended consequences of our curriculum.

\section{Conclusion}

The RUFDATA framework is a simple tool that we used to evaluate our teaching program. It can be widely applied to evaluate other areas in education. For example, it has been used to evaluate other focused medical topics (such as a training module to teach intrapartum care ${ }^{64}$ ) and even entire undergraduate university courses. ${ }^{65}$ In the future, we plan to evaluate other aspects of our communication curriculum such as crisis resource management, discharge summary dictations, and resident-to-resident patient care handover. We will also refine our tool that assesses the residents' communication with allied health professionals and explores options to involve patients and their families in the assessment. ${ }^{66,67}$

Although there are other frameworks that can be used to evaluate curricula, such Stufflebeam's CIPP ${ }^{68}$ and Kirkpatrick's Four-Level model, ${ }^{69}$ the RUFDATA framework's reflexive nature helps foster a culture of curricular evaluation by enhancing reflection on the reasons for the evaluation. Medical educators can easily apply this framework to evaluate their own curriculum.

\section{Disclosure}

The author reports no conflicts of interest in this work.

\section{References}

1. Goldie J. AMEE education guide no. 29: evaluating educational programmes. Med Teach. 2006;28(3):210-224.

2. DiFlorio I, Duncan P, Martin B, Middlemiss MA. Curriculum evaluation. Nurse Educ Today. 1989;9(6):402-407.

3. Coles CR, Grant JG. Curriculum evaluation in medical and health-care education. Med Educ. 1985;19(5):405-422.

4. Ouellet LL, Rush KL. Forces influencing curriculum evaluation. Nurse Educ Today. 1989;9(4):219-226.

5. Huwendiek S, Mennin S, Dern P, et al. Expertise, needs and challenges of medical educators: results of an international web survey. Med Teach. 2010;32(11):912-918.

6. Paritakul P, Wongwandee M, Tantitemit T, Pumipichet S, Dennick R. Level of confidence in the 12 roles of medical teacher. A descriptive study at Faculty of Medicine, Srinakharinwirot University, Thailand. J Med Assoc Thai. 2015;98(suppl 10):S38-S44.

7. Saunders M. Beginning an evaluation with RUFDATA: theorizing a practical approach to evaluation planning. Evaluation. 2000;6(1):7-21.

8. Frank JR, Snell L, Sherbino J. CanMEDS 2015 Physician Competency Framework; 2015. Available from: http://canmeds.royalcollege.ca/ uploads/en/framework/CanMEDS\%202015\%20Framework_EN_ Reduced.pdf. Accessed May 26, 2016.

9. ACGME. Accreditation Council for Graduate Medical Education Common Program Requirements; 2016. Available from: http://www.acgme. org/Portals/0/PFAssets/ProgramRequirements/CPRs_07012016.pdf. Accessed May 4, 2016.

10. Barrington K, Campbell B. MUDD mapping: an interactive teachinglearning strategy. Nurse Educ. 2008;33(4):159-163.

11. Azer SA, Guerrero AP, Walsh A. Enhancing learning approaches: practical tips for students and teachers. Med Teach. 2013;35(6):433-443.

12. Kurtz SM, Silverman J, Draper J. Teaching and Learning Communication Skills in Medicine. 2nd ed. Oxford: Radcliffe Pub; 2005.

13. Knox JDE, Bouchier IAD. Communication skills teaching, learning and assessment. Med Educ. 1985;19(4):285-289.

14. Stewart TL, Myers AC, Culley MR. Enhanced learning and retention through "writing to learn" in the psychology classroom. Teach Psychol. 2009;37(1):46-49.

15. Bagnasco A, Pagnucci N, Tolotti A, Rosa F, Torre G, Sasso L. The role of simulation in developing communication and gestural skills in medical students. BMC Med Educ. 2014;14(1):1-7.

16. Lewis R, Strachan A, Smith MM. Is high fidelity simulation the most effective method for the development of non-technical skills in nursing? A review of the current evidence. Open Nurs J. 2012;6:82-89.

17. Barry Issenberg S, McGaghie WC, Petrusa ER, Lee Gordon D, Scalese RJ. Features and uses of high-fidelity medical simulations that lead to effective learning: a BEME systematic review. Med Teach. 2005;27(1):10-28.

18. Berger W. The power of inquiry. A More Beautiful Question: The Power of Inquiry to Spark Breakthrough Ideas. 1st ed. Berger W, editor. New York, NY: Bloomsbury USA; 2014:20-48.

19. Chelimsky E. Introduction. In: Chelimsky E, Shadish WR, editors. Evaluation for the 21st Century: A Handbook. Thousand Oaks, CA: SAGE Publications; 1997:10.

20. Woods A. Exploring unplanned curriculum drift. J Nurs Educ. 2015;54(11):641-644.

21. Paul D, Ewen SC, Jones R. Cultural competence in medical education: aligning the formal, informal and hidden curricula. Adv Health Sci Educ Theory Pract. 2014;19(5):751-758.

22. Hafler JP, Ownby AR, Thompson BM, et al. Decoding the learning environment of medical education: a hidden curriculum perspective for faculty development. Acad Med. 2011;86(4):440-444.

23. Nyquist JG. The hidden curriculum in health professional education. J Chiropr Educ. 2016;30(1):48-49.

24. Hafferty FW. Beyond curriculum reform: confronting medicine's hidden curriculum. Acad Med. 1998;73(4):403-407. 
25. Hafferty FW, Gaufberg EH, O'Donnell JF. The role of the hidden curriculum in "on doctoring" courses. AMA J Ethics. 2015;17(2): $130-139$.

26. Scriven M. The methodology of evaluation. In: Tyler RW, Gagne RM, Scrivens M, editors. Perspectives of Curriculum Evaluation. 1st ed. Chicago, IL: Rand McNally; 1967:39-83.

27. Fiol CM, Lyles MA. Organizational learning. Acad Manage Rev. 1985;10(4):803-813.

28. Pascoe H, Gill SD, Hughes A, McCall-White M. Clinical handover: an audit from Australia. Australas Med J. 2014;7(9):363-371.

29. Wayne JD, Tyagi R, Reinhardt G, et al. Simple standardized patient handoff system that increases accuracy and completeness. J Surg Educ. 2008;65(6):476-485.

30. Gakhar B, Spencer AL. Using direct observation, formal evaluation, and an interactive curriculum to improve the sign-out practices of internal medicine interns. Acad Med. 2010;85(7):1182-1188.

31. Myers JS, Jaipaul CK, Kogan JR, Krekun S, Bellini LM, Shea JA. Are discharge summaries teachable? The effects of a discharge summary curriculum on the quality of discharge summaries in an internal medicine residency program. Acad Med. 2006;81(10 suppl):S5-S8.

32. Carnahan JL, Fletcher KE. Discharge education for residents: a study of trainee preparedness for hospital discharge. WMJ. 2015;114(5): 185-189.

33. Otto M, Sterling M, Siegler E, Eiss B. Assessing origins of quality gaps in discharge summaries: a survey of resident physician attitudes. J Biomed Educ. 2015;2015:341759.

34. Volk MS, Ward J, Irias N, Navedo A, Pollart J, Weinstock PH. Using medical simulation to teach crisis resource management and decisionmaking skills to otolaryngology housestaff. Otolaryngol Head Neck Surg. 2011;145(1):35-42.

35. Holzman RS, Cooper JB, Gaba DM, Philip JH, Small SD, Feinstein D. Anesthesia crisis resource management: real-life simulation training in operating room crises. J Clin Anesth. 1995;7(8):675-687.

36. Rudy SJ, Polomano R, Murray WB, Henry J, Marine R. Team management training using crisis resource management results in perceived benefits by healthcare workers. J Contin Educ Nurs. 2007;38(5): 219-226.

37. Tyler RW. How can the effectiveness of learning experiences be evaluated? In: Tyler RW, Hlebowitsh PS, editors. Basic Principles of Curriculum and Instruction. London: The University of Chicago Press, Ltd; 2013:117-138.

38. Scriven M. The nature of evaluation. New Dir Program Eval. 1993; 1993(58):5-48.

39. Caulley DN, Grotelueschen AD. The illusions of learner accomplishment. Educ Leadership. 1978;35(4):280.

40. Kelly AV. Assessment, evaluation, appraisal and accountability. The Curriculum: Theory and Practice. 6th ed. Kelly AV, editor. Thousand Oaks, CA: SAGE Publications, Inc; 2009:147-186.

41. Assis-Hassid S, Heart T, Reychav I, Pliskin JS, Reis S. Existing instruments for assessing physician communication skills: are they valid in a computerized setting? Patient Educ Couns. 2013;93(3):363-366.

42. Makoul G. The SEGUE framework for teaching and assessing communication skills. Patient Educ Couns. 2001;45(1):23-34.

43. Gustin JL, Way DP, Wells-Di Gregorio S, McCallister JW. Validation of the family meeting behavioral skills checklist: an instrument to assess fellows' communication skills. Ann Am Thorac Soc. 2016;13(8): 1388-1393.

44. Skillings JL, Porcerelli JH, Markova T. Contextualizing SEGUE: evaluating residents' communication skills within the framework of a structured medical interview. J Grad Med Educ. 2010;2(1): 102-107.

45. Peterson EB, Calhoun AW, Rider EA. The reliability of a modified Kalamazoo Consensus Statement Checklist for assessing the communication skills of multidisciplinary clinicians in the simulated environment. Patient Educ Couns. 2014;96(3):411-418.
46. Yuasa M, Nagoshi M, Oshiro-Wong C, Tin M, Wen A, Masaki K. Standardized patient and standardized interdisciplinary team meeting: validation of a new performance-based assessment tool. $J$ Am Geriatr Soc. 2014;62(1):171-174.

47. Schmitz CC, Chipman JG, Luxenberg MG, Beilman GJ. Professionalism and communication in the intensive care unit: reliability and validity of a simulated family conference. Simul Healthc. 2008;3(4):224-238.

48. Ponton-Carss A, Hutchison C, Violato C. Assessment of communication, professionalism, and surgical skills in an objective structured performance-related examination (OSPRE): a psychometric study. $\mathrm{Am}$ J Surg. 2011;202(4):433-440.

49. Cohen DS, Colliver JA, Robbs RS, Swartz MH. A large-scale study of the reliabilities of checklist scores and ratings of interpersonal and communication skills evaluated on a standardized-patient examination. Adv Health Sci Educ Theory Pract. 1996;1(3):209-213.

50. Cohen DS, Colliver JA, Marcy MS, Fried ED, Swartz MH. Psychometric properties of a standardized-patient checklist and rating-scale form used to assess interpersonal and communication skills. Acad Med. 1996;71(1 suppl):S87-S89.

51. Comert M, Zill JM, Christalle E, Dirmaier J, Harter M, Scholl I. Assessing communication skills of medical students in objective structured clinical examinations (OSCE) - a systematic review of rating scales. PLoS One. 2016;11(3): 0152717.

52. Tomlinson P, McAndrew R. An audit of the standard of response letters sent by hospital specialists to general dental practitioners following a referred patient's first appointment. Ann R Coll Surg Engl. 2005;87(4):251-254.

53. Fox AT, Palmer RD, Crossley JG, Sekaran D, Trewavas ES, Davies HA. Improving the quality of outpatient clinic letters using the Sheffield Assessment Instrument for Letters (SAIL). Med Educ. 2004;38(8):852-858.

54. Keely E, Myers K, Dojeiji S, Campbell C. Peer assessment of outpatient consultation letters - feasibility and satisfaction. BMC Med Educ. 2007;7:13.

55. Crossley GM, Howe A, Newble D, Jolly B, Davies HA. Sheffield Assessment Instrument for Letters (SAIL): performance assessment using outpatient letters. Med Educ. 2001;35(12):1115-1124.

56. McCain GA, Molineux JE, Pederson L, Stuart RK. Consultation letters as a method for assessing in-training performance in a department of medicine. Eval Health Prof. 1988;11(1):21-42.

57. Jack C, Hazel E, Bernatsky S. Something's missing here: a look at the quality of rheumatology referral letters. Rheumatol Int. 2012;32(4):1083-1085.

58. Darlow B, Donovan S, Coleman K, et al. What makes an interprofessional education programme meaningful to students? Findings from focus group interviews with students based in New Zealand. J Interprof Care. 2016;30(3):355-361.

59. Henzi D, Davis E, Jasinevicius R, Hendricson W. In the students' own words: what are the strengths and weaknesses of the dental school curriculum? J Dent Educ. 2007;71(5):632-645.

60. Cave J, Goldacre M, Lambert T, Woolf K, Jones A, Dacre J. Newly qualified doctors' views about whether their medical school had trained them well: questionnaire surveys. BMC Med Educ. 2007;7:38.

61. Leung KK, Wang WD, Chen YY. Multi-source evaluation of interpersonal and communication skills of family medicine residents. $A d v$ Health Sci Educ Theory Pract. 2012;17(5):717-726.

62. Gephart WJ. Who will engage in curriculum evaluation? Educ Leadership. 1978;35(4):255.

63. Conley-Tyler M. A fundamental choice: internal or external evaluation? Eval J Australas. 2005;4:3-11.

64. Mukhopadhyay S, Smith S. Curriculum evaluation from the trainees' perspective: application to the ALWP ATSM. J Obstet Gynaecol. 2010;30(8):795-799.

65. Sherman PD. Using RUFDATA to guide a logic model for a quality assurance process in an undergraduate university program. Eval Program Plann. 2016;55:112-119. 
66. Myerholtz L. Assessing family medicine residents' communication skills from the patient's perspective: evaluating the communication assessment tool. J Grad Med Educ. 2014;6(3):495-500.

67. Stausmire JM, Cashen CP, Myerholtz L, Buderer N. Measuring general surgery residents' communication skills from the patient's perspective using the communication assessment tool (CAT). J Surg Educ. 2015;72(1):108-116.
68. Stufflebeam DL. Daniel Stufflebeam's CIPP model for evaluation: an improvement- and accountability-oriented approach. In: Stufflebeam DL, Coryn CLS, editors. Evaluation Theory, Models, and Applications. 2nd ed. San Francisco, CA: Jossey-Bass; 2014:204-235.

69. Kirkpatrick DL, Kirkpatrick JD. Evaluating Training Programs: The Four Levels. 3rd ed. Oakland, CA: Berrett-Koehler Publishers; 2009.

\section{Publish your work in this journal}

Advances in Medical Education and Practice is an international, peerreviewed, open access journal that aims to present and publish research on Medical Education covering medical, dental, nursing and allied health care professional education. The journal covers undergraduate education, postgraduate training and continuing medical education including emerging trends and innovative models linking education, research, and health care services. The manuscript management system is completely online and includes a very quick and fair peer-review system. Visit http://www.dovepress.com/testimonials.php to read rea quotes from published authors.

Submit your manuscript here: http://www.dovepress.com/advances-in-medical-education-and-practice-journal 